with asthma who have not had life-threatening episodes in the past and are highly adherent to their drug regimen, it is likely that the use of salmeterol together with fluticasone in a single inhaler is safe. For these patients and this combination, the black-box warning should be lifted. This is an important result, and it stresses once again that most patients with asthma, and especially those without serious episodes, can reach high levels of symptom control and avoid frequent exacerbations by simply using their inhalers every day.

What remains unanswered is whether this conclusion applies to patients who have the most severe and unstable disease, since these are the patients for whom all guidelines still recommend the use of LABAs combined with inhaled glucocorticoids as first-line treatment. For these patients, the safe clinical approach is to maintain the same precautions in using fluticasonesalmeterol that have been recommended until now for all patients with asthma. In addition, the current trial evaluated patients 12 years of age or older. In one of the ongoing trials that are assessing adverse events associated with fluticasone-salmeterol (ClinicalTrials.gov number, NCT01462344), investigators are studying children between the ages of 4 years and 11 years. The results of this trial should provide much-needed data on the effect of these drugs in young children. It is also imperative to further explore the possibility that the presence of rare variants in genes associated with the response to beta-agonists may increase the risk of severe exacerbations when these drug combinations are administered to patients with the most severe asthma. ${ }^{8}$

Disclosure forms provided by the author are available with the full text of this article at NEJM.org.

From the Arizona Respiratory Center, University of Arizona, Tucson.

This article was published on March 6, 2016, at NEJM.org.

1. Nelson HS, Weiss ST, Bleecker ER, Yancey SW, Dorinsky PM. The Salmeterol Multicenter Asthma Research Trial: a comparison of usual pharmacotherapy for asthma or usual pharmacotherapy plus salmeterol. Chest 2006;129:15-26.

2. Castle W, Fuller R, Hall J, Palmer J. Serevent nationwide surveillance study: comparison of salmeterol with salbutamol in asthmatic patients who require regular bronchodilator treatment. BMJ 1993;306:1034-7.

3. Martinez FD. Safety of long-acting beta-agonists - an urgent need to clear the air. N Engl J Med 2005;353:2637-9.

4. Szefler SJ, Busse WW. The long-acting $\beta$-adrenergic agonist controversy in asthma: troublesome times! J Allergy Clin Immunol 2012;130:1256-9.

5. Mintz ML. Safety of long-acting beta-agonists. N Engl J Med 2006;354:1206-7.

6. Stempel DA, Raphiou IH, Kral KM, et al. Serious asthma events with fluticasone plus salmeterol versus fluticasone alone. N Engl J Med 2016;374:1822-30.

7. Turner MO, Noertjojo K, Vedal S, Bai T, Crump S, Fitzgerald JM. Risk factors for near-fatal asthma: a case-control study in hospitalized patients with asthma. Am J Respir Crit Care Med 1998;157:1804-9.

8. Ortega VE, Hawkins GA, Moore WC, et al. Effect of rare variants in ADRB2 on risk of severe exacerbations and symptom control during longacting $\beta$ agonist treatment in a multiethnic asthma population: a genetic study. Lancet Respir Med 2014;2: 204-13.

DOI: 10.1056/NEJMel601040

Copyright (๑) 2016 Massachusetts Medical Society.

\title{
MAGE-D2 and the Regulation of Renal Salt Transporters
}

\author{
Nine V.A.M. Knoers, M.D., Ph.D., and René J. Bindels, Ph.D.
}

Bartter's syndrome is a rare, genetically heterogeneous disorder characterized by renal salt wasting, hypokalemic metabolic alkalosis, and secondary hyperaldosteronism with normal to low blood pressure. Two distinct presentations of the syndrome exist: antenatal Bartter's syndrome and classical Bartter's syndrome. Both forms are inherited as autosomal recessive traits.

Patients with antenatal Bartter's syndrome may carry loss-of-function mutations in the genes encoding the furosemide-sensitive sodiumpotassium-chloride cotransporter NKCC2, the inwardly rectifying potassium channel ROMK, or the chloride channel $\beta$-subunit barttin. ${ }^{1}$ The concerted action of these transporters in the renal thick ascending limb of the loop of Henle ensures transcellular sodium chloride reabsorption in this nephron segment, which accounts for up to 20 to $25 \%$ of the total amount of filtered sodium chloride. In most persons with 
antenatal Bartter's syndrome, compromised function of the thick ascending limb of the loop of Henle clinically manifests in utero and is characterized by massive saliuretic polyuria resulting in severe polyhydramnios and premature birth. Postnatally, surviving patients with antenatal Bartter's syndrome have persistent salt wasting, hypokalemic metabolic alkalosis, hypercalciuria, and a tendency toward nephrocalcinosis. Patients with antenatal Bartter's syndrome are treated with fluid and salt supplementation and nonsteroidal antiinflammatory drugs, usually indomethacin. The latter agent should be administered with caution, because it may induce severe side effects, especially in preterm infants.

Remarkably, some patients with antenatal Bartter's syndrome have been described in whom the characteristic symptoms resolve spontaneously, fairly soon after birth. ${ }^{2,3}$ Until now, it was unclear whether this transient form of the condition was a distinct disorder. Now in the Journal, Laghmani et al. describe a genetic cause of this transient renal salt-wasting phenotype. ${ }^{4}$ All the patients with transient antenatal Bartter's syndrome who were available to the authors for study were male, so the authors predicted the involvement of an X-linked gene. Indeed, by means of whole-exome sequencing and filtering for X-chromosomal variants, Laghmani et al. identified in one of these families a loss-offunction mutation in MAGED2, on the X chromosome, that cosegregated with the disorder. This was followed by the detection of additional pathogenic MAGED2 mutations in other patients with transient antenatal Bartter's syndrome and in two families with idiopathic polyhydramnios. Overall, the study provides convincing evidence for the existence of a previously undescribed $\mathrm{X}$-linked form of severe polyhydramnios with prematurity and transient antenatal Bartter's syndrome caused by MAGED2 mutations.

Until recently, little was known about MAGED2 and the protein it encodes, melanoma-associated antigen D2 (MAGE-D2). MAGED2 belongs to a family of genes that are widely expressed in embryonic and adult tissues and are reported to be involved in cell-cycle regulation, apoptosis, and neurogenesis. ${ }^{5}$ MAGED2 has mainly been studied in the context of cancer ${ }^{6}$ and, on the basis of its location on Xp11.2 (a hotspot locus for X-linked mental retardation), has also been considered a candidate gene for X-linked intellectual disability. The finding of MAGED2 mutations in patients with transient antenatal Bartter's syndrome unravels a new, conspicuous role for MAGE-D2 in fetal renal salt reabsorption and, as a consequence, in amniotic fluid homeostasis. Laghmani et al. show that in fetal and adult kidneys, MAGE-D2 is expressed in the thick ascending limb of the loop of Henle and distal convoluted tubules, where it stimulates the plasma-membrane expression and activity of the salt transporter NKCC2 and the thiazide-sensitive sodium chloride cotransporter NCC, respectively. The authors also found reduced expression of both NKCC2 and NCC in a fetal kidney from a patient with antenatal Bartter's syndrome, which explains the massive salt loss.

The molecular mechanism proposed by the authors involves two MAGE-D2 binding partners: the molecular chaperone Hsp40 and cytoplasmic Gs-alpha. Under normal circumstances (i.e., in cells with wild-type MAGED2), the salt transporters are protected from endoplasmic reticulumassociated degradation by Hsp40 and can thus "pass" this quality-control checkpoint in the endoplasmic reticulum. Gs-alpha may participate in the vasopressin-induced cyclic AMP-signaling cascade and thereby stimulate the activity of NKCC2 and NCC by promoting their insertion into the plasma membrane. ${ }^{7,8}$

The transient nature of the salt-wasting phenotype is intriguing but unexplained. Laghmani et al. speculate that higher sensitivity of adenylate cyclase activity to vasopressin during development or increasing levels of oxygenation in the kidney during gestation might underlie this transience. Another potential explanation is the postnatal maturation of the renal tubules, which may result in an altered composition of transporters or their regulators and thereby compensate for the molecular defect. ${ }^{9}$ This maturation phenomenon has already been proposed to explain the transient neonatal hyperkalemia in patients with antenatal Bartter's syndrome caused by mutations of KCNJ1 (encoding ROMK). ${ }^{10}$

The recognition of polyhydramnios with transient antenatal Bartter's syndrome as a distinct $\mathrm{X}$-linked phenotype has clinical implications. Although there are no extant data from clinical trials, we think that women known to be preg- 
nant with a male fetus and who have unexplained severe polyhydramnios are candidates for genetic analysis of the fetus. An early genetic diagnosis would render other diagnostic measures for polyhydramnios unnecessary, and potentially harmful treatments, such as long-term treatment with indomethacin, could possibly be avoided in the preterm infants who survive.

Disclosure forms provided by the authors are available with the full text of this article at NEJM.org.

From the Department of Genetics and Center for Molecular Medicine, University Medical Center Utrecht, Utrecht (N.V.A.M.K.), and the Department of Physiology and Radboud Institute for Molecular Life Sciences, Radboud University Medical Center, Nijmegen (R.J.B.) — both in the Netherlands.

This article was published on April 27, 2016, at NEJM.org.

1. Seyberth HW, Schlingmann KP. Bartter- and Gitelman-like syndromes: salt-losing tubulopathies with loop or DCT defects. Pediatr Nephrol 2011;26:1789-802.

2. Reinalter S, Devlieger H, Proesmans W. Neonatal Bartter syndrome: spontaneous resolution of all signs and symptoms. Pediatr Nephrol 1998;12:186-8.
3. Engels A, Gordjani N, Nolte S, et al. Angeborene passagere hyperprostaglandinurische tubulopathie bei zwei frühgeborenen geschwistern. Mschr Kinderheilk 1991;139:185.

4. Laghmani K, Beck BB, Yang S-S, et al. Polyhydramnios, transient antenatal Bartter's syndrome, and MAGED2 mutations. N Engl J Med 2016;374:1853-63.

5. Barker PA, Salehi A. The MAGE proteins: emerging roles in cell cycle progression, apoptosis, and neurogenetic disease. J Neurosci Res 2002;67:705-12.

6. Papageorgio C, Brachmann R, Zeng J, Culverhouse R, Zhang W, McLeod H. MAGED2: a novel p53-dissociator. Int J Oncol 2007;31:1205-11.

7. Castrop H, SchießI IM. Physiology and pathophysiology of the renal Na-K-2Cl cotransporter (NKCC2). Am J Physiol Renal Physiol 2014;307:F991-1002.

8. Cheng L, Wu Q, Kortenoeven ML, Pisitkun T, Fenton RA. A systems level analysis of vasopressin-mediated signaling networks in kidney distal convoluted tubule cells. Sci Rep 2015;5: 12829.

9. Baum M, Quigley R, Satlin L. Maturational changes in renal tubular transport. Curr Opin Nephrol Hypertens 2003;12:521-6. 10. Finer G, Shalev H, Birk OS, et al. Transient neonatal hyperkalemia in the antenatal (ROMK defective) Bartter syndrome. J Pediatr 2003;142:318-23.

DOI: 10.1056/NEJMe1603856

Copyright (C) 2016 Massachusetts Medical Society. at NEJMjobs.org for more information. 